\title{
ALTERNATIVAS PARA O CONTROLE DE NEMATOIDES GASTRINTESTINAIS DE PEQUENOS RUMINANTES
}

\author{
M.B. Molento ${ }^{1}$, C.J. Veríssimo ${ }^{2}$, A.T. Amarante ${ }^{3}$, \\ J.A. van Wyk ${ }^{4}$, A.C.S. Chagas ${ }^{5}$, J.V. de Araújo ${ }^{6}$, F.A. Borges ${ }^{7}$
}

${ }^{1}$ Universidade Federal do Paraná, Setor de Ciências Agrárias, Departamento de Medicina Veterinária, Laboratório de Doenças Parasitárias, Rua dos Funcionários, 1540, CEP 80035-050, Curitiba, PR, Brasil. E-mail: molento@ufpr.br

\section{RESUMO}

A criação de ovinos e caprinos depende de um manejo eficiente, devido, principalmente, ao prejuízo causado por parasitos em animais susceptíveis. Vários fatores colaboram para que os animais tolerem as infecções parasitárias, como: genética, nutrição, estado fisiológico e idade. O grave problema causado pela resistência anti-helmíntica promoveu a difusão de técnicas alternativas de controle parasitário. Dentre essas novas estratégias incluem-se a adoção do tratamento parcial seletivo com o método FAMACHA, fitoterapia, controle biológico com o uso de fungos nematófagos e estratégias que ainda necessitam de mais dados como a homeopatia, a diluição da resistência com a introdução de parasitos sensíveis e a combinação de produtos químicos sem efeito antiparasitário. O objetivo central destes métodos é reduzir o uso de antiparasitários, retardando o desenvolvimento da resistência, e promover melhor utilização de produtos ainda eficazes na propriedade e de novos produtos que venham a ser lançados. Este artigo abordará as técnicas descritas acima para o controle de nematoides de pequenos ruminantes e é direcionado aos técnicos interessados em ampliar seu conhecimento sobre os mecanismos de resistência dos parasitos aos anti-helmínticos e de alternativas ao uso desses produtos.

PALAVRAS-CHAVE: Anti-helmíntico, homeopatia, fitoterapia, Famacha, controle biológico, resistência parasitária.

\section{ABSTRACT}

ALTERNATIVETECHNIQUESFORTHECONTROLOFGASTROINTESTINAL NEMATODES IN SMALL RUMINANTS. Sheep and goat farming requires an efficient management program, due to losses caused by parasites in susceptible animals. Many factors may collaborate to improve infection tolerance in the herd, such as: genetics, nutrition, physiological status, and age. The problem caused by resistance to antihelmintic agents has led to the spread of alternative techniques for parasite controls. The latest strategies include selective treatment with the FAMACHA method, phytotherapy, biological control with predatory fungi, and strategies that still await scientific confirmation, such as homeopathy, the dilution of resistance with the introduction of susceptible parasites, and the combination of drugs without antihelmintic effect. The main objective of these methods is to reduce the usage of antiparasitic agents, thus slowing the development of resistance and promoting the better use of effective products and newly released products. The objective of this article is to describe techniques for controlling nematodes in small ruminants, and it is aimed at technicians interested in increasing their knowledge about the mechanisms of resistance to antihelmintic agents as well as alternatives to the use of these products.

KEY WORDS: Sheep, goats, phytotherapy, FAMACHA, biological control, parasite resistance.

${ }^{2}$ Instituto de Zootecnia, Centro de Pesquisa em Zootecnia Diversificada, Nova Odessa, SP, Brasil.

${ }^{3}$ Universidade Estadual Paulista, Instituto de Biociências, Departamento de Parasitologia, Botucatu, SP, Brasil.

${ }^{4}$ University of Pretoria, Department of Veterinary Tropical Diseases, Onderstepoort, Africa do Sul.

${ }^{5}$ Embrapa Pecuária Sudeste, São Carlos, SP, Brasil.

${ }^{6}$ Universidade Federal de Viçosa, Departamento de Veterinária, Viçosa, MG, Brasil.

${ }^{7}$ Universidade Federal do Mato Grosso do Sul, Faculdade de Medicina Veterinária Zootecnia, Campo Grande, MS, Brasil. 
A saúde do rebanho ovino e caprino depende, entre outros fatores, de um controle sanitário efetivo. A verminoseécausada por várias espécies de helmintos que parasitam o trato gastrintestinal e representa um dos principais problemas sanitários nas criações de pequenos ruminantes, causando consideráveis prejuízos econômicos, tais como, retardo no desenvolvimento, diminuição na produção de carne, leite, lã, gastos com a compra de anti-helmínticos e até mortalidade (TAYLOR et al., 2007).

A resistência que os nematoides gastrintestinais, particularmenteHaemonchus contortus, Trichostrongylus sp., Oesophagostomum sp. e Cooperia sp., vêm adquirindo aos anti-helmínticos tem sido uma grandelimitação no controle da verminose (KAPLAN et al., 2004).

A eficácia dos produtos antiparasitários é alcançada quando são associados os fatores relativos às suas características farmacológicas, à fisiologia do hospedeiro e ao(s) parasito(s) em questão (NARI; EDDI, 2003). A determinação do fator de resistência dos parasitos aos grupos químicos (benzimidazoles, levamisole, substitutos fenólicos, salicilanilidas, e avermectinas/ milbemicinas) promoveu grande investimento em pesquisa sobre os mecanismos de resistência. A resistência parasitária é um dos problemas mais sérios da cadeia produtiva, com a substituição acelerada do alelo SS, homozigoto susceptível, por alelo(s) RR, homozigoto resistente (MotTIER; PRICHARd, 2008).

A partir das evidências de resistência às drogas, os registros de problemas com a verminose começaram a ser mais comuns, incluindo relatos de resistência múltipla. VAN WYK et al. (1999) descreveram uma população de $H$. contortus resistente a cinco grandes grupos de anti-helmínticos, incluindo a moxidectina. Atualmente, é comum encontrar resistência às lactonas macrocíclicas e outros grupos químicos no Brasil e no mundo (Veríssimo et al., 2012). Para evitar que novos compostos e aqueles que ainda têm eficácia em uma população de pequenos ruminantes venham ser descartados em função do fenômeno da resistência anti-helmíntica são necessárias medidas que prolonguem a vida útil dessas drogas.

Este artigo abordará algumas técnicas alternativas de controle da verminose em pequenos ruminantes, incluindo a descrição do mecanismo de resistência dos parasitos às drogas, e reversão química da resistência, com o objetivo de informar os interessados em ampliar seu conhecimento no assunto.

\section{Mecanismos de resistência aos anti-helmínticos}

O grande desafio é conhecer profundamente o mecanismo de resistência das drogas e suas possíveis formas de interação molecular. Como regra, aceita-se que o mecanismo de resistência esteja ligado ao mecanismo de ação dos medicamentos
(Molento et al., 1999). RAO et al. (2009) e SKUCE et al. (2010) apontaram para mecanismos cada vez mais complexos e polimorficamente variados entre as espécies de parasitos, sendo os potenciais mecanismos de resistência parasitária; a modificação do receptor no local de ação da molécula; o aumento do efluxo da droga na parede celular através da glicoproteína de permeabilidade (P-gp); caminhos alternativos de inibição da ação da droga; aumento na concentração substratos/enzimas nos locais de ação; falha na ativação da droga; e a mudança no metabolismo/ excreção da droga.

\section{Benzimidazóis}

Os nematodas, assim como outros helmintos, fungos e alguns protozoários, têm locais de ligação com alta afinidade pelo benzimidazole hidrofóbico. Esses locais de alta afinidade foram localizados na porção N-terminal da b-tubulina. Foi também descoberto que uma fenilalanina na posição 200 confere com o gene de isolados susceptíveis em $H$. contortus a uma tirosina (F200Y) na mesma posição de isolados resistentes. Esse gene tem característica dominante também para Trichostrongylus colubriformis (SILVESTRE; HumberT, 2002). No entanto, sabe-se que existem outros pontos de mutação importantes que causam a resistência, como a posição 167 e 198, tanto em $H$. contortus como em T. colubriformis (PRICHARD, 2001; GHISI et al., 2007).

Lactonas Macrocíclicas (avermectinas/milbemicinas)

Estudos recentes apontam o envolvimento dos canais de cloro, da b-tubulina e da P-gp como os principais fatores ligados ao mecanismo de resistência em H. contortus e T. colubriformis (MOtTIER; PRICHARD, 2008). Foi relatado que existem dois membros da família dos canais de cloro responsáveis pela resistência às drogas, um na faringe e outro no sistema nervoso do parasito (CONDER; CAMPBELL, 1995). A função da P-gp é retirar produtos nocivos do interior, ou da parede, da célula em vários organismos através do que se denomina efluxo celular ativo (GotTESMAN; PASTAN, 1993). Xu etal. (1998) observaram que os níveis de RNA mitocondrial de P-gp em $H$. contortus foram mais altos em isolados resistentes à ivermectina do que em susceptíveis.

\section{Imidotiazóis (levamisole)}

Ainda são necessários vários esclarecimentos quanto ao processo de seleção do levamisole, embora se suspeite que a resistência envolva a perda de sensibilidade nas subunidades UNC38, UNC29, UNC63, LEV1 e ACR13 do receptor colinérgico e em outros locais do parasito (MARTIN; ROBERTSON, 2007).

Atualmente, grandes avanços na genética molecular estão contribuindo para o melhor entendi- 
mento da resistência parasitária com o objetivo de desenvolver marcadores moleculares. GILLEAR; BEECH (2007) afirmaram que se pode determinar o grau de interação e a distância entre regiões polimórficas no genoma dos parasitas. Nos helmintos, a distância entre a região que codifica para o canal de cloro foi estimada em $1 \mathrm{~kb}$ para $H$. placei com uma outra região polimórfica (MES, 2004).

\section{Reversão química da resistência}

\section{Inibição da glicoproteína-P (P-gp)}

O primeiro gene associado a resistência às lactonas macrocíclicas em $H$. contortus foi o responsável pela expressão da P-gp. Essa proteína é membro da família de transportadores do tipo ABC (ATP-binding cassete). A P-gp está envolvida nos processos de absorção, metabolismo e distribuição de substâncias químicas estranhas ao organismo (MEALEY, 2004). O aumento da expressão da P-gp está relacionado à resistência de células cancerígenas humanas a quimioterápicos, uma vez que age transportando a droga para fora da célula tumoral. Esse fenômeno é denominado resistência múltipla a drogas (RMD), pois pode envolver vários grupos químicos (GOTTESMAN; PASTAN, 1993). A RMD foi observada em H. contortus e T. colubriformis, parasitos de ovinos no Brasil (AlmeIDA et al., 2010).

\section{Agentes moduladores da P-gp}

Molento; PRICHARD (1999) verificaram a possibilidade da utilização do verapamil, uma droga com efeito antiarrítmico cardíaco, como droga moduladora da P-gp na reversão da resistência antihelmíntica. $\mathrm{O}$ aumento da atividade anti-helmíntica de ivermectina e de moxidectina associada ao verapamil foi observado em um modelo experimental utilizando cobaias (Meriones unguiculatus) experimentalmente infectadas com larvas de $H$. contortus resistentes. Além do efeito direto na reversão à resistência anti-helmíntica, a inibição da P-gp por drogas moduladoras aumenta a biodisponibilidade do anti-helmíntico, aumentando, consequentemente, a eficácia contra nematoides resistentes (MoLENTO et al., 2004b). BorGEs et al. (2011) realizaram um estudo em ovinos experimentalmente infectados com um isolado de $H$. contortus resistente à ivermectina, aplicando esta concomitantemente ao verapamil em veículo aquoso (três aplicações em intervalos de 12 horas); a eficácia foi de 36,02\%. Esse valor foi 4,6 vezes maior que o apresentado pelo endectocida administrado isoladamente, demonstrando uma reversão parcial da resistência desse nematoide à ivermectina. Isso pode ser explicado, pois no teste in vitro foram utilizadas altas concentrações de verapamil, o que não seria possível no teste com ovinos devido a possível ocorrência de efeitos adversos, conforme descrito por Molento; PRICHARD (1999). LifCHITZ et al. (2010), ao utilizarem loperamida como agente reversor, in vivo, da resistência através da modulação da P-gp sobre a atividade anti-helmíntica em ovinos, observaram mudanças na concentração plasmática e eficácia de ivermectina. A meia-vida de ivermectina foi prolongada na presença do modulador e aumentou a eficácia contra $H$. contortus e $T$. colubriformis em 72,5 e $96,3 \%$ respectivamente na contagem de vermes post mortem.

\section{Método FAMACHA}

O método FAMACHA, palavra que reúne as iniciais do nome de seu idealizador, o pesquisador sul-africano Faffa Malan, acrescentada das três primeiras letras da palavra cartão em inglês (chart), consiste em um cartão que apresenta cinco cores, correspondentes ao grau de coloração da mucosa ocular. VAN WYK; BATH (2002) demonstraram, após vários testes de campo, alta correlação entre o grau de tonalidade da conjuntiva e o resultado do volume globular. Na Tabela 1 estão descritas as cores e a correspondente variação no volume globular, bem como a atitude clínica a tomar.

Tabela 1 - Informações contidas no cartão FAMACHA, grau de anemia e coloração da conjuntiva, correspondente ao volume globular (VG) e atitude a tomar com relação ao tratamento dos animais.

\begin{tabular}{clcc}
\hline $\begin{array}{c}\text { Grau } \\
\text { FAMACHA }\end{array}$ & Coloração* & $\begin{array}{c}\text { Variação do } \\
\text { VG (\%) }\end{array}$ & $\begin{array}{c}\text { Atitude } \\
\text { clínica** }^{*}\end{array}$ \\
\hline 1 & Vermelhorobusto & Acima de 28 & Não tratar \\
2 & Vermelho rosado & 23 a 27 & Não tratar \\
3 & Rosa & 18 a 22 & Tratar \\
4 & Rosa pálido & 13 a 17 & Tratar \\
5 & Branco & Abaixo de 12 & Tratar \\
\hline
\end{tabular}

*A estimativa das cores deve ser aproximada devido à divergência de interpretaçãono momento do exameclínico. **A indicação do tratamento antiparasitário no cartão é baseada unicamente na coloração da conjuntiva.

O objetivo do método FAMACHA é identificar animais anêmicos que não são aptos a tolerar a hemoncose (doença causada pelo $H$. contortus, o verme que se alimenta de sangue e que por isso pode causar anemia que, dependendo da gravidade, pode levar o animal à morte). Aqueles que se encontram com os graus 3,4 ou 5 receberão o vermífugo, permitindo que o restante do rebanho permaneça sem tratamento. MolEnTO et al. (2004a) determinaram que existe ainda alta correlação entre o grau FAMACHA e o valor de hematócrito tanto em animais anêmicos como em sadios. O princípio do método FAMACHA reside na curva do tipo bino- 
mial negativo que rege a distribuição dos parasitos em uma população de hospedeiros, ou seja, uma minoria de animais dentro da população alberga a maioria dos parasitas; de modo, então, que é possível tratar essa minoria, deixando os outros sem receber tratamento, o que permite a existência de abundante parcela da população de parasitos não expostos ao vermífugo, a chamada população em "refugia". A falha na manutenção de uma população em refugia é o fator mais significativo no processo de seleção parasitária e em seu desenvolvimento (VAN WYK, 2001).

MaLAn et al. (2001) demonstraram que o número de tratamentos antiparasitários pode ser reduzido com o método FAMACHA. Assim, em experimentos conduzidos em pastagem irrigada sob condições de hemoncose severa, os autores verificaram que $90 \%$ das ovelhas que não estavam em gestação e/ou em lactação foram capazes de permanecer sem tratamento, comparado com $73 \%$ dos animais prenhes e $45 \%$ dos animais lactantes. Molento etal. (2009) sugeriram que o método FAMACHA é capaz de revelar um efeito hospedeiro-específico que age regulando as taxas de infecção, manifestando claramente a característica resistente/resiliente dentro do rebanho com benefícios econômicos importantes.

Entretanto, CARDIA et al. (2011), em São Paulo, constataram que $T$. colubriformis também causa prejuízo econômico (menor desempenhoe conversão alimentar). Esse verme não pode ser diagnosticado pelo métodoFAMACHA, já quenão causa anemia na mesma proporção que Haemonchus. Os sinais causados por esse verme, assim como Oesophagostomum sp., verme comum em muitos estados brasileiros, geralmente são fezes diarreicas (que sujam a lã ou o pelo na região posterior dos animais), pelo arrepiado, sem brilho, e emagrecimento. Portanto, os técnicos e pecuaristas deverão ficar atentos para esse fato e medicar também algum animal que apresente esses sinais, mesmo que esteja com a mucosa ocular apresentando grau 1 ou 2.

\section{Reversão temporária da resistência com trata- mento seletivo e introdução de parasitos sensíveis}

Até o ano 2004, o controle parasitário do sistema de produção intensiva de ovinos para corte do Instituto de Zootecnia de Nova Odessa, SP, se caracterizava pela aplicação de anti-helmíntico em todos os animais do rebanho, três a quatro vezes ao ano, e com rápida rotação de grupos químicos disponíveis no comércio. A partir daquele ano, foi verificada a ineficácia de todos os grupos químicos, e os tratamentos passaram a ser realizados de forma curativa e/ou tática. Entre os anos de 2000 a 2008, a eficácia da moxidectina neste rebanho passou de 0 a $86 \%$, e a eficácia do levamisole que era de $99 \%$ em
2000, e chegou a $0 \%$ em 2004, atingiu 97\% em 2008 (Veríssimoet al. 2008). A eficácia nula da moxidectina, observada após quatro anos de uso, talvez tenha sido devido à resistência lateral à ivermectina, constatada no ano de 1996 (3 anos após sua introdução e utilização na propriedade). Com relação ao levamisole, constatou-se alta eficácia no ano 2000, após cerca de 10 anos de não uso devido a histórico de ineficiência (VERíssimo et al. 2002); essa eficácia foi sendo perdida gradativamente ao longo dos anos, até atingir níveis mínimos (0\%) em 2004, com grande aumento nos anos de 2007 e 2008 (Veríssimo et al. 2008). Uma das explicações para o aumento da eficácia após o ano de 2004, é que no ano de 2005 houve a introdução de 60 animais, e, entre eles, estavam 25 da raça Morada Nova, criados extensivamente, com baixo grau de utilização de anti-helmínticos. É provável que esses animais tenham introduzido uma população de nematoides geneticamente sensíveis, o que contribuiu para a aceleração do processo de reversão temporária da resistência. Em 2006 foram introduzidas 40 ovelhas da raça Suffolk e 40 da raça Ile de France, sem histórico de resistência à moxidectina e ao levamisole, podendo novamente ter contribuído com a chegada de parasitos com histórico susceptível a esses anti-helmínticos e, igualmente, contribuído com o processo de reversão temporária da resistência a esses produtos; o método FAMACHA adotado nessa ocasião também colaborou para menor uso de anti-helmínticos no rebanho e, consequentemente, para a manutenção de uma população refugia sensível a anti-helmínticos.

SisSAY et al. (2006) também conseguiram, em um período de sete meses, reverter uma situação de resistência parasitária a anti-helmínticos em cabras, simplesmente tirando esses animais de ondeestavam e colocando-os em um outro local, onde ficavam ovinos sem histórico de resistência.

\section{Raças tolerantes aos parasitos}

Algumas raças de ovinos são mais tolerantes geneticamenteàs infecções por nematoides gastrintestinais. A criação de ovinos resistentes pode ser utilizada como ferramenta na profilaxia da verminose ovina, já que esses animais suportam maior desafio aos parasitos e eliminam quantidade significativamente menor de ovos nas fezes, resultando na diminuição da contaminação da pastagem por larvas infectantes (BAssetTo et al., 2009).

Bricarello et al. (2004), no Rio Grande do Sul, demonstraram que a resistência à infecção por $H$. contortusémuito superior nos animais da raça Crioula Lanada do que em animais da raça Corriedale. Em São Paulo, AMARANTE et al. (2004) demonstraram em cordeiros, Costa et al. (2007) em borregas e BUENo et al. (2002) em ovelhas, maior tolerância da raça Santa 
Inês à infecção por nematoides gastrintestinais do que animais de raças lanadas. Ovelhas da raça Santa Inês também foram mais resistentes, apresentando menor número de ovos eliminados nas fezes no período do periparto (RocHA et al., 2004).

Entretanto, animais da raça Santa Inês produzem carcaça de qualidade inferior a de animais de raças especializadas. No caso da produção de cordeiros destinados ao abate, o cruzamento de matrizes da raça naturalmente mais resistente, Santa Inês, com reprodutores de raças mais produtivas, tais como Dorper, Texel, Suffolk ou Ile de France, é uma alternativa viável, que aumenta a produtividade dos cordeiros mestiços sem aumentar a suscetibilidade à verminose (AMARANTE et al., 2009).

A característica resistência à verminosenos ovinos é herdável, com herdabilidades estimadas entre 0,2 e 0,4, indicando que ganhos genéticos podem ser alcançados em rebanhos que incluem a característica resistência à verminose no programa de seleção (Windon, 1996; WoOlAston; BAKER, 1996).

Alguns fatores relacionados à resposta imunológica dos animais interferem em sua resistência, tolerância ou suscestibilidade à verminose.

\section{Nutrição (estado nutricional)}

Animais que recebem alimentação com altos níveis de proteína podem apresentar aumento na capacidade para tolerar as consequências adversas do parasitismo. Associado a isso, podem, ainda, limitar o estabelecimento de larvas infectantes, o desenvolvimento e a fecundidade dos nematódeos e, até mesmo, causar a eliminação dos parasitos já estabelecidos no trato gastrintestinal. Por último, o alimento pode afetar diretamente os helmintos ao conter compostos antiparasitários, o que ocorre, por exemplo, com plantas ricas em tanino condensado (CoOP; KYRIAZAKIS, 2001; BRUneT et al., 2007).

Dietas com teor elevado de proteína propiciam melhor eficiência na resposta imunológica, especialmente daquelas raças que já são naturalmente mais resistentes à hemoncose (BRICARELLO et al., 2005). Para implantar melhor oferta alimentar, o rebanho deve ser separado em categorias, favorecendo a nutrição adequada e diminuindo os custos de produção, por evitar gastos desnecessários com categorias menos exigentes (ovelhas sem cria, ovelhas até o terceiro mês de gestação e carneiros fora de estação de monta). Dessa maneira, as diferentes categorias podem ser submetidas a sistemas de alimentação diferenciados, como: manutenção exclusiva em pastagem, pastagem com suplementação de volumosos e/ou concentrados, e ou confinamento.

\section{$\underline{\text { Período do periparto }}$}

No período de periparto (último mês de gestação e durante a lactação), ocorre um aumento na eliminação de ovos nas fezes, com consequente aumento da contaminação da pastagem (BARGER, 1996). BEASLEY et al. (2010) verificaram que, após a desmama dos cordeiros, a resposta imunológica da ovelha se restabelece, indicada pelo aumento de eosinófilos e $\operatorname{IgG}_{1}$, IgM e IgE, provocando redução acentuada na contagem de OPG (ovos por grama de fezes). É interessante salientar que o fenômeno do periparto apresenta intensidade variável conforme a raça. Nas raças que apresentam melhor tolerância aos nematoides, o fenômeno do periparto, quando ocorre, é mais discreto do que o observado em raças ovinas susceptíveis (AMARANTE et al., 1999; RocHA et al., 2004; Rocha et al., 2011).

CoOP; KYRIAZAKIS (2001) determinaram que as ovelhas apresentam uma necessidade relativamente elevada de proteína metabolizável no final da gestação e durante a lactação. As proteínas podem ser consideradas como um nutriente escasso na rotina dos rebanhos do Brasil e o seu consumo geralmente é insuficiente para atender à demanda dos animais neste período.

VALDERRÁBANO et al. (2006) sugeriram que existe uma relação muito grande entre o bom estado nutricional da ovelha nos primeiros 90 dias de gestação e a resposta imune no período periparto, associado ao acúmulo de gordura corporal e níveis de leptina. Houdijk et al. (2005) enfatizaram que embora a suplementação proteica represente um custo relativamente elevado para a atividade, possibilita que, as fêmeas suplementadas aumentem a produção de leite, o que resulta em maior ganho de peso dos cordeiros e, inclusive, permite reduzir o uso de anti-helmínticos.

$\underline{\text { Idade }}$

A susceptibilidade à verminose é muito maior em animais jovens do que nos adultos, devido principalmente à fraca resposta imunológica contra o ataque dos parasitos. Segundo ScHALLIG (2000), cordeiros jovens não apresentam uma boa resposta protetora de células de defesa tipo-Th2, o que se reflete em número reduzido de mastócitos e de eosinófilos na mucosa do abomaso. Porém, em genótipos mais resistentes aos nematoides gastrintestinais, como algumas raças naturalizadas das Américas, os cordeiros podem apresentar resposta imunológica contra os parasitos desde muito cedo, quando comparados a raças suscetíveis (AMARANTE et al., 2004).

\section{Fitoterapia}

Embora existam atualmente métodos que permitam o monitoramento dos extratos vegetais, a possibilidade de variabilidade dos princípios ativos e, consequentemente, da reprodutibilidade das pesquisas, dificulta o desenvolvimento e o registro de fitoterápicos para o controle parasitário. Segundo 
GobBo-Neto; Lopes (2007), vários fatores podem influenciar a produção de metabólicos secundários, que são considerados uma fonte importante de substâncias ativas vegetais, como: temperatura, ritmo circadiano, disponibilidade hídrica, radiação ultravioleta, altitude e indução por estímulos mecânicos ou ataque de patógenos. Acredita-se que, com a intensificação de estudos fitoquímicos de espécies de interesse, exista mais conhecimento disponível com relação aos fatores de influência de produção das substâncias ativas vegetais. ROMERO (2007) sugeriu que o crescimento de uma ferramenta da genômica funcional, conhecida como metabolômica, possibilitará a identificação e a quantificação das substâncias ativas por meio de métodos cromatográficos, da espectrometria de massa e da ressonância magnética nuclear.

\section{Azadirachta indica (Nim)}

Essa espécie tem sido bastante investigada com o objetivo de validar seu uso no controle de nematoides gastrintestinais de pequenos ruminantes. $\mathrm{O}$ princípio ativo mais importante do Nim, árvore de origem indiana, é a azadirachtina contida nas folhas da planta, mas principalmente na semente e fruto. Pietrosemoli et al. (1999) determinaram que o fornecimento de folhas parcialmente desidratadas pode reduzir o OPG em bovinos. Ovelhas que receberam $3 \mathrm{~g} / \mathrm{kg}$ de folhas frescas de Nim por 6 semanas sofreram redução significativa na contagem de parasitas adultos. Onúmero de vermes foi verificado por meio de necropsia, entretanto, o tratamento não refletiu na contagem do OPG em relação ao grupo controle (Chandrawathani et al. 2006). Por outro lado, trabalhos têm demonstrado ineficácia no uso do Nim. Ovelhas infectadas artificialmente com larvas de $H$. contortus e T. colubriformis receberam extrato etanólico de sementes de Nim, na dose de $3 \mathrm{mg} / \mathrm{kg}$ de peso vivo. No $13^{\circ}$ dia após a administração, a eficácia na redução do OPG foi de 5,2\% e na redução de vermes adultos na necropsia foi de 0\% (HÖRDEGEN et al., 2003). Grupos de cinco ovelhas receberam folhas frescas de Nim nas doses de 250, 500 e $1.000 \mathrm{mg} / \mathrm{kg}$ por três semanas. Nos dois últimos tratamentos foi observada redução no consumo alimentar eaumento significativo do OPG (GITHIORI et al.,2004). CHAGAs; VIEIRA (2007) não observaram efeito anti-helmíntico do Nim na dose de $30 \mathrm{~g}$ de folhas secas por cabra/dia fornecido por cinco dias. OOPG foi monitorado diariamente por 28 dias no grupo tratado e controle com 12 cabras cada. CHAGAs et al. (2008) determinaram que ovelhas da raça Morada Nova recebendo respectivamente $12.5,25.0$ e $37.5 \mathrm{~g} /$ animal de folhas de $A$. indica (Meliaceae), fenadas, trituradas e incorporadas ao milho não foram eficientes no controle dos nematoides gastrintestinais. IQBAL et al. (2010) obtiveram redução máxima de
OPG $(40,2 \%)$ somente no $15^{\circ}$. dia pós-tratamento em ovelhas que receberam o extrato metanólico das sementes de $A$. indica na dose de $3 \mathrm{~g} / \mathrm{kg}$ PV. Essa dose representa um volume significativo a ser produzidoe administrado oralmente aos animais, demonstrando baixa praticidade. Diante do exposto, $A$. indica não se apresenta como uma espécie para uso potencial no controle de nematoides gastrintestinais.

\section{Homeopatia}

Os estudos com o uso da homeopatia populacional para auxílio no manejo sanitário de rebanhos são relativamente recentes (LATHOUD, 2001). VERÍSSIMO (2008) realizou uma revisão sobre uso de homeopatia para controle da verminose e chegou à conclusão que medicamentos homeopáticos, embora muitas vezes não controlem efetivamente a população de parasitas nos animais, torna-os mais tolerantes à infecção, promovendo ganho de peso. ZACARIAS et al. (2008) encontraram efeitos favoráveis de medicamentos homeopáticos, com diminuição significativa $(P<0,01)$ do número de larvas de $H$. contortus em coproculturas provenientes dos animais que receberam os medicamentos homeopáticos, e ganho de peso maior do que aqueles que receberam o produto químico, obtendo avaliação positiva de custo/benefício. CAVALCANTI et al. (2008) forneceram 10 gotas deSulphur $30 \mathrm{CH}$ diluído em água, uma vez ao dia, para cordeiros da raça Santa Inês, durante 72 dias, quando seis animais de cada tratamento foram abatidos para recuperação dos helmintos do trato gastrintestinal. $\mathrm{O}$ medicamento homeopático promoveu aumento dos níveis de IgG $(\mathrm{P}<0,05)$ em relação ao tratamento com ivermectina injetável no início do experimento, e um grupo controle que recebeu somenteágua diariamente. Entretanto, CHAGAS et al. (2008) e RocHA et al. (2006) não observaram efeitos positivos do produto comercial homeopático Fator Vermes ${ }^{\circledast}$, administrado diariamente a ovinos por pelo menos seis meses consecutivos.

A homeopatia só deverá ser utilizada como forma decontrole parasitário se mais estudos comprovarem sua aplicabilidade e se adequarem à rigorosidade científica, sendo reproduzíveis em vários locais, e com várias raças, e, devido a sua complexidade, seu uso deverá ser monitorado por profissionais especializados, pois doses ou medicamentos incorretos podem levar a reações adversas que podem piorar o quadro clínico dos animais.

\section{Controle biológico (fungos nematófagos)}

Até o momento, somente a aplicação de fungos nematófagos foi validada como uma forma eficiente de controle biológico, sendo as demais alternativas (anelídeos, protozoários, bactérias e vírus) pouco 
pesquisadas. A ação dos fungos nematófagos é dividida em três grupos: predadores, endoparasitoides e oportunistas ou parasitos de ovos, podendo ser isolados do solo, fezes, esterco e outros ambientes como estabelecido por DUdDINGTON (1955).

Os fungos predadores, ao passarem pelo trato gastrintestinal, limitam-se às fezes, onde têm grande crescimento miscelial e, posteriormente, no solo, permanecem como esporos. Em caprinos, micélio do fungo Monacrosporium sinense e M. appendiculatum passaram pelo trato gastrintestinal sem perda de capacidade em predar as $\mathrm{L}_{3}$ de $H$. contortus de caprinos (Assis et al., 2005). Melo et al. (2003) conseguiram a passagem do fungo $M$. thaumasium pelo trato gastrintestinal de caprinos, sem perda de viabilidade para predar larvas infectantes de $H$. contortus. Um experimento que utilizou ovinos como animais experimentais determinou que Arthrobotrys oligospora, A. oviformis e Geniculifera eudermata foram capazes de resistir ao estresse de passagem pelo trato gastrintestinal dos animais sem perda de capacidade predatória sobre $H$. contortus (WALLERetal.1994). A administração diária, por quatro meses, de clamidósporos de Duddingtonia flagrans, administrados em grãos decevada para ovinos criados em sistema extensivo, foi responsável pela redução da carga parasitária de Nematodirius spathiger, $N$. battus, no intestino delgado, além de Ostertagia sp. e Trichostrongylus sp. no abomaso (GITHIGIA et al. 1997).

A administração de fungos deve prever que este seja fornecido em longos períodos, e que tenha como alvo as formas dos parasitos presentes no bolo fecal em quantidade suficiente para realizar uma inundação ambiental com as estruturas fúngicas.

\section{Considerações finais}

Existe grande consenso entre pesquisadores e profissionais que trabalham com assistência técnica de que os programas de controle parasitário em uso na atualidade não fornecem a segurança obtida em décadas passadas. Este fato é decorrente da dependência da utilização de produtos químicos, principalmente na atividade de criação de pequenos ruminantes. Resultados recentes apontam para a difusão, também através do comércio de animais, de populações parasitárias que apresentam resistência múltipla aos três grupos químicos de amploespectro.

As técnicas abordadas neste artigo de revisão, embora sem a intenção de esgotar o assunto, foram escolhidas com o objetivo de informar sobre novas possibilidades de pesquisa, incluindo o aprimoramento eimplementação de uma rotina de diagnóstico visando à manutenção da saúde animal em ambiente com alto nível de desenvolvimento técnico e rápida transferência de tecnologia. $\mathrm{O}$ tratamento seletivo com o método FAMACHA é o melhor exemplo da implantação de um sistema que engloba o entendimento do efeito da população parasitária em refugia e a redução da resistência no mundo todo, gerando uma nova realidade no campo, capacitando profissionais e diferenciando o controle sanitário.

A criação de ovinos resistentes aos parasitos poderá contribuir significativamente para reduzir a dependência atual da utilização de anti-helmínticos para o controle da verminose, assim como o uso de drogas moduladoras da P-gp associado às macrolactonas poderá ser uma importante ferramenta no aumento da vida útil dos anti-helmínticos. Muito embora estas duas técnicas tenham vasto material cientifico, ainda são necessárias a realização de estudos para determinar o grau de herdabilidade de indivíduos selecionados e a formulação farmacêutica do agente modulador, principalmente, em relação à sua concentração.

Apesar de todos os avanços realizados na pesquisa com fungos nematófagos, extratos vegetais e medicamentos homeopáticos como controladores de parasitos gastrintestinais, alguns obstáculos impedem a sua indicação imediata como, por exemplo, a dose efetiva, produção em larga escala, a falta de comprovação científica e de validação multicentro, o potencial de risco ambiental e, sobretudo, o impacto de sua utilização no bem-estar animal. Esta última preocupação é real visto que os resultados abordados neste documento indicam uma eficácia marginal das formas de controle onde os animais poderão ser mantidos com um nível relativo de parasitismo.

\section{REFERENCIAS}

ALMEIDA, F.A.; GARCIA, K.C.O.D.; TORGERSON, P.R.; AMARANTE, A.F.T. Multiple resistance to anthelmintics by Haemonchus contortus and Trichostrongylus colubriformis in sheep in Brazil. Parasitology International, v.59, n.4, p.622-625, 2010.

AMARANTE, A.F.T.; CRAIG, T.M.; RAMSEY, W.S.; EL-SAYED, N.M.; DESOUKI, A.Y.; BAZER, F.W. Comparison of naturally acquired parasite burdens among Florida Native, Rambouillet and crossbred ewes. Veterinary Parasitology, v.85, n. 1, p.61-69, 1999.

AMARANTE, A.F.T.; BRICARELLO, P.A.; ROCHA, R.A.; GENNARI, R.M. Resistance of Santa Ines, Suffolk and Ile de France sheep to naturally acquired gastrointestinal nematode infections, Veterinary Parasitology, v.120, n.2, p.91-106, 2004.

AMARANTE, A.F.T.; SUZIN, I.; ROCHA, M.B.; MENDES, C.Q.; PIRES, A.V. Resistance of Santa Ines and crossbred ewes to naturally acquired gastrointestinal nematode infections. Veterinary Parasitology, v.165, n.3, p.273-280, 2009. 
ASSIS, R.C.L.; ARAÚJO, J. V.; GANDRA, J.R.; CAMPOS, A.K. Avaliação de fungos predadores de nematóides do gênero Monacrosporium sobre larvas infectantes de Haemonchus contortus de caprinos. Revista Brasileira de Ciência Veterinária, v.12, n.1/3, p.42-45, 2005.

BARGER, I. A prospects for of novel parasite control opotions into grazing systems. International Journal for Parasitology, v. 26, n.8/9, p.1001-1007, 1996.

BASSETTO, C.C.; SILVA, B.F.; FERNANDES, S.; AMARANTE, A.F.T. Contaminação da pastagem com larvas infectantes de nematóides gastrintestinais após o pastejo de ovelhas resistentes ou suscetíveis à verminose. Revista Brasileira de Parasitologia Veterinária, v.18, n.4, p.63-68, 2009.

BEASLEY, A.M.; KAHN, L.P.; WINDON, R.G. The periparturient relaxation of immunity in Merino ewes infected with Trichostrongylus colubriformis: parasitological and immunological responses. Veterinary Parasitology, v.168, n.1/2, p.60-70, 2010.

BORGES, F.A.; ROSSINI, J.B.; VELLUDO, P.P.; BUZZULINI, C.A.; COSTA, G.H.; MOLENTO, M.B.; COSTA, A.J. Weak phenotypic reversion of ivermectin resistance in a field resistant isolate of Haemonchus contortus by verapamil. Pesquisa Veterinária Brasileira, v. 31, n.9, p.731-736, 2011.

BRICARELLO, P. A; GENNARI, S.M.; OLIVEIRASEQUEIRA, T.C.G.; VAZ, C.M.S.L.; GONÇALVES, I.G.; ECHEVARRIA, F.A.M. Worm burden and immunological responses in Corriedale and Crioula Lanada sheep following natural infection with Haemonchus contortus. Small Ruminant Research, v.51, p.73-81, 2004.

BRICARELLO, P.A.; AMARANTE, A.F.T.; ROCHA, R.A.; CABRAL FILHO, S.L.; HUNTLEY, J.F.; HOUDIJK, J.G.M.; ABDALLA, A.L.; GENNARI, S.M. Influence of dietary protein supply on resistance to experimental infections with Haemonchus contortus in Ile de France and Santa Ines lambs. Veterinary Parasitology, v.134, p.99-109, 2005.

BRUNET, S.; AUFRERE, J.; EL BABILI, F.; HOSTE, H. The kinetics of exsheathment of infective nematode larvae is disturbed in the presence of a tanin-rich plant extract (sainfoin) both in vitro and in vivo. Parasitology, v.134, p.1253-1262, 2007.

BUENO, M.S.; CUNHA, E.A.; VERÍSSIMO, C.J.; SANTOS, L.E.; LARA, M.A.C.; OLIVEIRA, S.M.; SPÓSITO FILHA, E.; REBOUÇAS, M.M. Infección por nematódeos em razas de ovejas carnicas criadas intensivamente en la región del sudeste del Brasil. Archivos de Zootecnia, v.51, p.273-280, 2002.

CARDIA, D.F.F.; ROCHA-OLIVEIRA, R.A.; TSUNEMI, M.H.; AMARANTE, A.F.T. Immune response and performance of growing Santa Ines lambs to artificial Trichostrongylus colubriformis infections. Veterinary Parasitology, v.182, p.248-258, 2011.
CAVALCANTI, A.; AYRES, M.C.C.; ECHEVARRIA, F.A.M.; RIBEIRO, F.S.; LIMA, F.W.M.; GUDES M.T.B. Efeito do medicamento Sulphur sobre nematódeos gastrintestinais resistentes a ivermectina de cordeiros infectados naturalmente. In: CONGRESSO BRASILEIRO DE PARASITOLOGIA VETERINÁRIA, 15., 2008. Curitiba, Brasil. Anais. Curitiba: Colégio Brasileiro de Parasitologia Veterinária, 2008. 1-CD-ROM.

CHAGAS, A.C.S.; VIEIRA, L.S. Ação ovicida in vitro e in vivo de Azadirachta indica (Neem) em nematodeos gastrintestinais de caprinos. Brazilian Journal of Veterinary Research and Animal Science, v.44, p.49-55, 2007.

CHAGAS, A.C.S.; VIEIRA, L.S.; FREITAS, A.R.; ARAÚJO, M.R.A.; ARAÚJO-FILHO, J.A.; ARAGUÃO, W.R.; NAVARRO, A.M.C. Anthelmintic efficacy of neem (Azadirachta indica a. juss) and the homeopathic product Fator Vermes in Morada Nova sheep. Veterinary Parasitology, v.151, n.1, p.68-73, 2008.

CHANDRAWATHANI, P.; CHANG, K.W.; NURULAINI, R.; WALLER, P.J.; ADNAN, M.; ZAINI, C.M.; JAMNAH, O.; KHADIJAH, S.; VINCENT, N. Daily feeding of fresh Neem leaves (Azadirachta indica) for worm control in sheep. Tropical Biomedicine, v.23, p.23-30, 2006.

CONDER, G.A.; CAMPBELL, W.C. Chemotherapy of nematode infections of veterinary importance, with special reference to drug resistance. Advances in Parasitology, v.35, n.1, p.1-84, 1995.

COOP, R.L.; KYRIAZAKIS, I. Influence of host nutrition on the development and consequences of nematode parasitism in ruminants. Trends in Parasitology, v.7, n.6, p.325-330, 2001.

COSTA, R.L.D.; BUENO, M.S.; VERÍSSIMO, C.J.; CUNHA, E.A.; SANTOS, L.E.; OLIVEIRA, E.M.; SPÓSITO-FILHA, E.; OTSUK, I.P. Performance and nematode infection of ewe lambs on intensive rotational grazing with two different cultivars of Panicum maximum. Tropical Animal Health Production, v.39, p.255-263, 2007.

DUDDINGTON, C.L. Notes on the technique of handling predaceous fungi. Transactions of the British Mycology Society, v.38, p.97-103, 1955.

GHISI, M.; KAMINSKY, R.; MÄSER, P. Phenotyping and genotyping of Haemonchus contortus isolates reveals a new putative candidate mutation for benzimidazole resistance in nematodes. Veterinary Parasitology, v.144, p.313-320, 2007.

GILLEARD, J.S.; BEECH, R.N. Population genetics of anthelmintic resistance in parasitic nematodes. Parasitology, v.134, n.9, p.1133-1147. 2007.

GITHIGIA, S.M.; THAMSBORG, S.M.; LARSEN, M.; KYVSGAARD, N.C.; NANSEN, P. The preventive effect of the fungus Duddingtonia flagrans on Trichostrongyle 
infections of lambs on pasture. International Journal for Parasitology, v.27, n.8, p.931-939, 1997.

GITHIORI, J.B.; HÖGLUND, J.; WALLER, P.J.; BAKER, R.L. Evaluation of anthelmintic properties of some plants used as livestock dewormers against Haemonchus contortus infections in sheep. Parasitolology, v.129, p.245-253, 2004.

GOBBO-NETO, L.; LOPES, N.P. Plantas medicinais: fatores de influência no conteúdo de metabólitos secundários. Química Nova, v.30, n.2, p.374-381, 2007.

GOTTESMAN, M.M.; PASTAN, I. Biochemistry of multidrug resistance mediated by the multidrog transporter. Annuals Review of Biochemistry, v.62, n.1, p.385-427, 1993.

HÖRDEGEN, P., HERTZBERG, H., HEILMANN, J., LANGHANS, W., MAURER, V. The anthelmintic efficacy of five plant products against gastrointestinal trichostrongylids in artificially infected lambs. Veterinary Parasitology, v.117, p.51-60, 2003.

HOUDIJK, J.G.M.; KYRIAZAKIS, I.; JCKSON, F.; HUNTLEY, J.F.; COOP, R.L. Effects of protein supply and reproductive status on local and systemic immune responses to Teladorsagia circumcincta in sheep. Veterinary Parasitology, v.129, n.2, p.105-117, 2005.

IQBAL, Z.; LATEEF, M.; JABBAR, A.; GILANI, A.H. In vivo anthelmintic activity of Azadirachta indica a. Juss seeds against gastrointestinal nematodes of sheep. Veterinary Parasitology, v.168, p.342-345, 2010.

KAPLAN, R.M.; BURKE, J.M.; TERRIL, T.H.; MILLER, J.E.; GETZ, W.R.; MOBINI, S.; VALENCIA, E.; WILLIAMS, M.J.; WILLIAMSON, L.H.; LARSEN, M.; VATTA, A.F. Validation of the FAMACHA ${ }^{\odot}$ eye color chart for detecting clinical anaemia in sheep and goats on farms in southern United States. Veterinary Parasitology, v.123, n.1, p.105-120, 2004.

LATHOUD, J.A. Estudos de matéria médica homeopática. 1.ed. São Paulo: Editora Organon, 2001. 1149p.

LIFSCHITZ, A.; ENTROCASSO, C.; ALVAREZ, L.; LLOBERAS, M.; BALLENT, M.; MANAZZA, G.; VIRKEL, G.; BORDA, B.; LANUSSE, C. Interference with P-glycoprotein improves ivermectin activity against adult resistant nematodes in sheep. Veterinary Parasitology, v.172, p.291-298, 2010.

MALAN, F.S.; VAN WYK, J.A.; WESSELS, C.A. Clinical evaluation of anaemia in sheep: early trials. Onderstepoort Journal of Veterinary Research, v.68, n1, p.195-174, 2001.

MARTIN, R.J.; ROBERTSON, A.P. Mode of action of levamisole and pyrantel, anthelmintic resistance, E153 and Q57. Parasitology, v.134, n.7, p.1093-1104, 2007.
MEALEY, K.L. Therapeutic implications of the MDR-1 gene. Journal of Veterinary Pharmacology and Therapeutics, v.27, n.3, p.257-264, 2004.

MELO, L. M.; BEVILAQUA, C.M.L.; ARAÚJO, J.V.; MELO, A.C.F.L. Atividade predatória do fungo Monacrosporium thaumasium contra o nematóide Haemonchus contortus, após passagem pelo trato gastrintestinal de caprinos. Ciência Rural, v.33, n.1, p.169-171, 2003.

MES, T.H. Purifying selection and demographic expansion affect sequence diversity of the ligant-binding domain of a glutamate-gated chloride channel gene of Haemonchus placei. Journal of Molecular Evolution, v.58, n.3, p.466-478, 2004.

MOLENTO, M.B.; PRICHARD, R.K. Effects of the multidrug-resistance-reversing agents verapamil and CL 347,099 on the efficacy of ivermectin or moxidectin against unselected and drug-selected strains of Haemonchus contortus is jirds (Meriones unguiculatus). Parasitology Research, v.85, p.1007-1011, 1999.

MOLENTO, M.B.; PRICHARD, R.K. Effect of multidrug resistance modulators on the activity of ivermectin and moxidectin against selected strains of Haemonchus contortus infective larvae. Pesquisa Veterinária Brasileira, v.21, n.1, p.117-121, 2001.

MOLENTO, M.B.; WANG, G.T.; PRICHARD, R.K. Decrease ivermectin and moxidectin sensitivity in Haemonchus contortus selected with moxidectin over 14 generations. Veterinary Parasitology, v.86, n.1, p.77-81, 1999.

MOLENTO, M.B.; TASCA, C.; GALLO, A.; FERREIRA, M.; BONONI, R.; STECCA, E. Método FAMACHA como parâmetro clínico individual de infecção por Haemonchus contortus em pequenos ruminantes. Ciência Rural, v.34, n.2, p.1139-1145, 2004a.

MOLENTO, M.B.; LIFSCHITZ, A.; SALLOVITZ, J.; LANUSSE, C.; PRICHARD, R. Influence of verapamil on the pharmacokinetics of the antiparasitic drugs ivermectin and moxidectin in sheep. Parasitology Research, v.92, p.121-127, 2004b.

MOLENTO, M.B.; GAVIÃO, A.A.; DEPNER, R.A.; PIRES, C.C. Frequency of treatment and production performance using the FAMACHA method compared with preventive control in ewes. Veterinary Parasitology, v.162, n.3/4, p.314-319, 2009.

MOTTIER, M.L.; PRICHARD, R.K. Genetic analysis of a relationship between macrocyclic lactone and benzimidazole anthelmintic selection on Haemonchus contortus. Pharmacogenetics Genomics, v.18, n.2, p.129-140, 2008.

NARI, A.; EDDI, C. Resistance to ecto and endo-parasites. A challenge for the XXI century? In: INTERNATIONAL SEMINAR IN ANIMAL PARASITOLOGY, 5., 2003, 
Merida, México. Anais. Merida: Food and Drug Organization/FAO, 2003. v.1. p.53-60.

PIETROSEMOLI, S; OLAVEZ, R.; MONTILLA, T.; CAMPOS, Z. Empleo de hojas de Neem (Azadirachta indica A. Juss) en control de nematodos gastrointestinales de bovinos a pastoreo. Revista de la Facultad de Agronomia, v.16, n.2, p.220-225, 1999.

PRICHARD, R.K. Genetic variability following selection of Haemonchus contortus with anthelmintics. Trends in Parasitology, v.17, n.4, v.445-453, 2001.

RAO, V. T.S.; SIDDIQUI, S.Z.; PRICHARD, R.K.; FORRESTER, S.G. A dopamine gated ion channel (HcGGR3) from Haemonchus contortus is expressed in the cervical papillae and is associated with macrocyclic lactone resistance. Molecular and Biochemical Parasitology, v.166, n.1, p.54-61, 2009.

ROCHA, R.A.; AMARANTE, A.F.T.; BRICARELLO, P.A. Comparison of the susceptibility of Santa Inês and Ile de France ewes to nematode parasitism around parturition and during lactation. Small Ruminant Research, v.55, n.1, p.65-75, 2004.

ROCHA, R.A.; BRICARELLO, P.A.; SILVA, M.B.; HOUDIJK, J.G.M.; ALMEIDA, F.A.; CARDIA, D.F.F.; AMARANTE, A.F.T. Influence of protein supplementation during late pregnancy and lactation on the resistance of Santa Ines and Ile de France ewes to Haemonchus contortus. Veterinary Parasitology, v.181, n.2/4, p.229-238, 2011.

ROCHA, R.A.; PACHECO, R.D.L.; AMARANTE, A.F.T. Efficacy of homeopathic treatment against natural infection of sheep by gastrointestinal nematodes. Revista Brasileira de Parasitologia Veterinária, v.15, n.1, p.23-27, 2006.

ROMERO, T. Em busca de novos princípios ativos. Boletim da Agência FAPESP. 2007. 62p.

SCHALLIG, H.D.F.H. Immunological responses of sheep to Haemonchus contortus. Parasitology, v.120, p.S63-S72, 2000.

SILVESTRE, A.; HUMBERT, J.F. Diversity of benzimidazoleresistance alleles in population of small ruminant parasites. International Journal for Parasitology, v.32, n.6, p.921-928, 2002.

SISSAY, M.M.; ASEFA, A.; UGGLA, A.; WALLER, P.J. Anthelmintic resistance of nematode parasites of small ruminants in eastern Ethiopia: Exploitation of refugia to restore anthelmintic efficacy. Veterinary Parasitology, v.135, n.3/4, p. 337-346, 2006.

SKUCE, P.; STENHOUSE, L.; JACKSON, F.; HYPŠA, V.; GILLEARD, J. Benzimidazole resistance allele haplotype diversity in United Kingdom isolates of Teladorsagia circumcincta supports a hypothesis of multiple origins of resistance by recurrent mutation. International Journal for Parasitology, v.40, p.1247-1255, 2010.

TAYLOR, M.A.; COOP, R.L.; WALL, R.L. Veterinary parasitology. 3.ed. Oxford: Blackwell Publishing, 2007. 874p.

VALDERRÁBANO, J.; GOMEZ-RINCÓN, URIARTE, J. Effect of nutritional status and fat reserves on the periparturient immune response to Haemonchus contortus infection in sheep. Veterinary Parasitology, v.141, n.1/2, p.122-131, 2006.

VAN WYK, J.A. Refugia-overlooked as perhaps the most potent factor concerning the development of anthelmintic resistance. Onderstepoort Journal of Veterinary Research, v.68, n.1, p.55-67, 2001.

VAN WYK, J.A.; BATH, G.F. The FAMACHA system for managing haemonchosis in sheep and goats by clinically identifying individual animals for treatment. Veterinary Research, v.33, n.5, p.509-529, 2002.

VAN WYK, J.A.; STENSON, M.O.; VAN DER MERWE, J.S.; VORSTER, R.J.; VILJOEN, P.G. Anthelmintic resistance in South Africa: Surveys indicate an extremely serious situation in sheep and goat farming. Onderstepoort Journal of Veterinary Research, v.66, n. 3, p.273-284, 1999.

VERÍSSIMO, C.J. Homeopatia e controle da verminose. In: VERÍSSIMO, C.J. (Ed.) Alternativas de controle da verminose em pequenos ruminantes. Nova Odessa: Instituto de Zootecnia, p. 65-71, 2008. Disponível em: <http:/ / www.iz.sp.gov.br/pdfs/1249593677.pdf>. Acesso: 25 jan. 2012.

VERÍSSIMO, C. J.; OLIVEIRA, S.M.; SPÓSITO-FILHA, E. Eficácia de alguns anti-helmínticos em uma ovinocultura no Estado de São Paulo, Brasil. In: CONGRESSO BRASILEIRO DE PARASITOLOGIA VETERINÁRIA, 12., 2002, Rio de Janeiro, RJ. Anais. Rio de Janeiro: Colégio Brasileiro de Parasitologia Veterinária, 2002. 1-CD-ROM.

VERÍSSIMO, C.J.; KATIKI, L.M.; BUENO, M.S.; CUNHA, E.A. Reversão da resistência de nematóides gastrintestinais em rebanho ovino. In: CONGRESSO BRASILEIRO DE PARASITOLOGIA VETERINÁRIA, 15., 2008, Curitiba, PR. Anais. Curitiba: Colégio Brasileiro de Parasitologia Veterinária, 2008. 1-CD-ROM.

VERÍSSIMO, C.J.; NICIURA, S.C.M.; ALBERTI, A.L.L.; RODRIGUES, C.F.C.; BARBOSA, C.F.C.; CHIEBAO, D.P.; CARDOSO, D.; SILVA, G.S.; PEREIRA, J.R.; MARGATHO, L.F.F.; COSTA, R.L.D.; NARDON, R.F.; UENO, T.E.H.; CURCI, V.C.L.M.; MOLENTO, M.B. Multidrug and multispecies resistance in sheep flocks from São Paulo state, Brazil. Veterinary Parasitology, v.187, n.1/2, p.209-216, 2012.

WALLER, P.J.; LARSEN, M.; FAEDO, M.; HENNESSY, D.R. The potential of nematophagous fungi to control 
free-living stages of nematodes parasites of sheep: in vitro and in vivo studies. Veterinary Parasitology, v.51, n.3, p.289-299, 1994.

WINDON, R.G. Genetic control of resistance to helminths in sheep. Veterinary Immunology and Immunopatology, v.54, p.245-254, 1996.

WOOLASTON, R.R.; BAKER, R.L. Prospects of breeding small ruminants for resistance to internal parasites. International Journal for Parasitology, v.26, n.6, p,845-855, 1996.

XU, M.; MOLENTO, M.; BLACKHALL, W.; RIBEIRO, P.; BEECH, R.; PRICHARD, R. Ivermectin resistance in nematodes may be caused by alteration of P-glycoprotein homolog. Molecular and Biochemical Parasitology, v.91, n.3, p.327-335, 1998.

ZACARIAS, F., GUIMARÃES, J.E.; ARAÚJO, R.R.; ALMEIDA, M.A.O.; AYRES, M.C.C.; BAVIA, M.E.; MENDONÇA-LIMA, F.W. Effect of homeopathic medicines on helminth parasitism and resistance of Haemonchus contortus infected sheep. Homeopathy, v.97, p.145-151, 2008.

Recebido em 8/3/12

Aceito em 10/4/13 